\title{
Destination Governance and a Strategic Approach to Crisis Management in Tourism
}

\author{
Bindi Varghese \\ School of Business Studies and Social Sciences, Christ University, Bannerghatta Road Campus, Bangalore, India
}

Email address:

bindi.varghese@christuniversity.in

\section{To cite this article:}

Bindi Varghese. Destination Governance and a Strategic Approach to Crisis Management in Tourism. Journal of Investment and Management. Vol. 5, No. 1, 2016, pp. 1-5. doi: 10.11648/j.jim.20160501.11

Received: June 2, 2016; Accepted: June 12, 2016; Published: July 18, 2016

\begin{abstract}
Tourism is a strategic economic activity in Karnataka, but the uniqueness of the governing bodies accentuates on integrated planning pioneering with several distinguishing features. The urban and territorial changes caused by tourism are well introspected areas in contemporary scientific literature. This research adopts an integrative approach with a framework connecting scientific traditions of destination management and competitiveness with a case study examining in-depth reliability of Destination Management Organizations (DMOs) in destination governance and narrates upon the essentiality of stakeholder participation in destination decision making process. Most pertinent functions of the Destination Management Organization (DMO) are to facilitate the corporation and collaboration of stakeholder within the destination. Primarily in times of crisis where collaboration and collective decision making is a priority; many destinations today are not equipped to combat such crisis which consecutively take a toll on the destination and unfavourably affect the tourists visiting the destination leaving behind a negative impression which can adversely affect the tourism integrity of the destination.
\end{abstract}

Keywords: Governance, Stakeholders Collaboration, Destination Management Organization's (DMOs), Crisis/Disaster Management

\section{Introduction}

Destinations must be well equipped to tackle an exceptional circumstances such as terror attacks, spread of diseases, natural disasters and so on. A pivotal concern the destination has to address is ensuring the safety and security of the tourists, which is the responsibility of the host destination. The safety and security measure provisioned by the destination encourage tourist visits and promotes the healthy growth of the tourism and hospitality industry. Thus, it is a value-creation system which inturn demands interorganizational cohesion especially in a crisis situation, the implication of which projects the requirement of a destination to encompass a collaborative environment.

Baggio, Scott and Cooper [3] portrays the tourist destination as a group of interrelated stakeholders deeprooted in a societal set of connections where they intermingle and mutually meet tourist wants and develop the experience of the travellers. So the origin of governance is a relationship that exists between numerous stakeholders and their interaction with one another.

Here the role of Destination Management Organizations (DMOs) (henceforth this abbreviation would be used in the article) comes to play an active role in handling such situations. These bodies of control are responsible for managing all the activities of the destination in terms of both marketing and management besides this another important functionality of the DMO is destination governance. Destination governance is necessary to manage the complex nature of tourist destinations effectively. To arrive at conclusions and decision making the collaborative efforts of all stakeholders of the destination is necessary. A DMO provides an open forum for stakeholders to address their opinions and enables collective decision making which is crucial in a trying situation.

\section{DMO in Building a Synergy Between Destination and Stakeholders}

A DMO is usually a local body, where the DMO meta- 
manager is one of the local agencies with few financial resources or where there exists no DMO and the destination is managed by the leading or a private company. The DMOs can be segmented into 'wealthy DMOs', 'neither rich nor poor DMOs' and 'poor' DMOs.

The main financial resource of DMOs is composed of the income given by the associated members and the products sold, also an amount is gained through compensation but this depends on the seasonality, customer retention and so on. Based on this Angella, Carlo \& Sainaghi [2] have formed four archetypes described as follows: First model is based on the local authority that guarantees the local political representation of interests where the finances are either public or private in certain situations both. Second model is based on entrepreneurship where voluntary members are formed. Third model is in the form of leading firms, where a single entity is represented by a local body. Lastly, the fourth model is on the bases of the fragmented characteristics of the tourist destinations that have faced a sudden surge in tourism demand.

These depict the boundaries within which a DMO functions it illustrates the various strengths and weaknesses of governance and exuberates on the various roles that the DMO play, it even highlights that the DMO administrators need to be cautiously selected. It is very essential to have a synergy between Destination Management mechanisms and Stakeholder alliance for effective collaboration. This paper postulates an Indicative Framework for integrating destination management and stakeholder engagement with alliance.

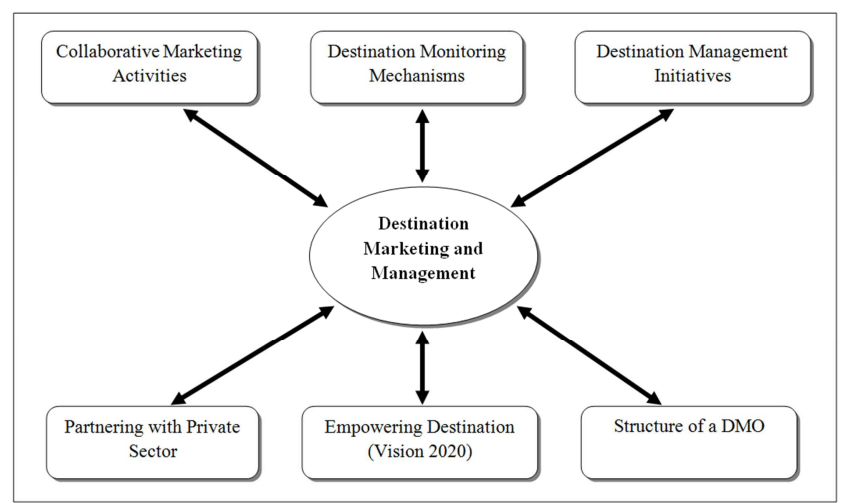

Figure 1. Indicative Framework for Destination Management and Stakeholder alliance.

\section{Destination Governance Guide}

A destination may choose its governance style differential in order to achieve the goals set by the destination. For example the study conducted by Del Chippa [6] who looked into the destination governance of Emerald coast were the governance was spread across three organizations: Municipality, Consortium and Starwood each responsible to various categories. The municipality dealt with laws responsible for planning, the consortium for financial resources where it's the owner of the brand logo but has no functions of marketing and finally Starwood where it deals with influencing destination image through advertising and promotions.

Palmer [7] speaks of how there is a dire need for a systematic approach in governance tools as with the wrong means of governance several collaborative tourism destination marketing associations would fail. The system of governance can be 'loose' or 'tight' modelled, wherein there is a formal or an informal medium of control.

\section{DMOs in Stakeholder Collaboration}

The stakeholders of a destination can be managed in many other ways as Bregoli and Del Chippa [5] describes how the stakeholders can be coordinated by the DMOs how this coordination or destination governance will impact the stakeholders. The study was focused on Edinburgh where two partnerships Destination Edinburgh Marketing Alliance (DEMA) and Edinburgh Tourism Action Group (ETAG) were identified. The study found that both the organizations utilized the same kind of coordination methods that is social norms: ETAG was seen to be more trusted than DEMA. ETAG used internal communication; information systems were used to interact with the stakeholders, selection systems, interlocking directorates, planning and control systems and finally formal rules.

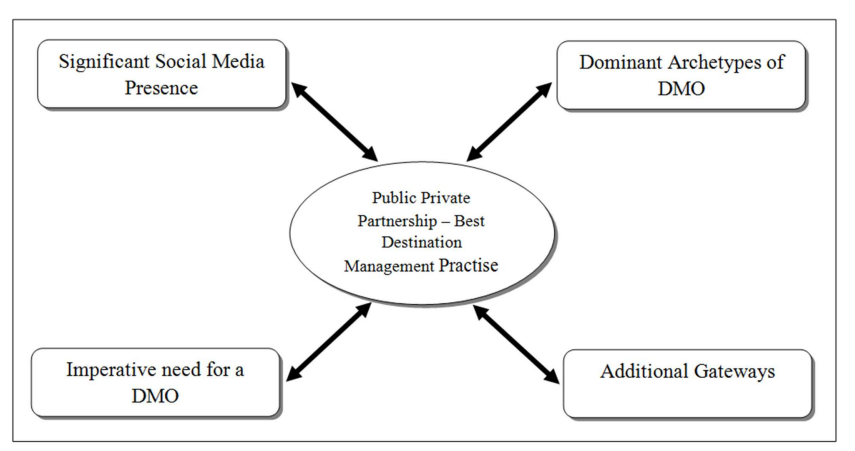

Figure 2. Indicative Framework of Collaboration.

Therefore, a DMO is directly or indirectly in contact with the stakeholders of the region and must consider their opinion while making important destination decisions.

\section{Need for Collaborative Decision Making in a Crisis Situation}

Strobl and Peters [12] defines governance as, "a diverse set of governing elements and modules acting together on different spatial levels, as well as the procedure of a collective agency coordinating stakeholders and organizations in order to achieve common objectives" (p.60). So invariably Governance is viewed as the collaborative efforts of both the destination and the stakeholders therein as Angella, Carlo and Sainaghi [2] explains through an in-depth study on the importance of stakeholder's participation in the Destination Management Organization's (DMOs) activities and connects this to destination governance. Essentially in a 
crisis situation the collaborative efforts and cooperation of all is called for, therefore the contributions offered by the stakeholders that is the private organizations, NGOs and residents as well as their help in the decision making process in the destination management organizations is vital.

In the analysis of literature conducted by Angella, Carlo and Sainaghi [2] the authors showcase the various pros and cons of destination governance which are summarized as follows: though stakeholder participation is encouraged it may result in a lack of a consensus between them as depicted in Emerald coast by Dell Chippa [6] where there was found no inter-organizational dialogue between the parties, the level of trust, collaboration and reciprocity between the stakeholder's was low. It was noted that the existing relationship between the operators and their DMOs was not good as there was low level of coordination carried out by the DMO, a lack of trustworthiness of DMO managers, low level of leadership and a new level of collaboration and coordination in building branding strategy and positioning. This lack of coordination caused the rise of confusion amongst the tourists.

Hence the DMOs must take initiative in managing stakeholder coordination which should be based on aspects of trust, risk sharing as well as strategic consensus. So the collaborative relationships or partnerships may vary according to the different kinds of stakeholders involved in destination governance.

Network methods have been used to recognize stakeholders of a destination who contribute towards the development of tourism activities, and to destination governance. Unified inter-organizational networks are necessary in creating integrated tourism experiences, as it is this unified trait which can be used as the vantage point to authority and power over others. Network analysis and its applications are recommended to tourism researchers and policy makers. Baggio, Scott \& Cooper, [3].

Strobl and Peters [12] cites the example of Seefield where the DMO is made up of the supervisory board, board of directors, two executives with the addition two more actors being tourism entrepreneurs and landowners who play an important role in the development of the destination. These actors in the destination exhibit individual and collective behaviour though the cooperation skills are mediocre presently they are improving gradually, these actors come together in times of crisis as joint decision making is required. "In other instances, the DMO serves as a hub firm, or a facilitator, providing a map for destination tourism development. It can also function as a 'controller', permitting firms to carry out certain activities, such as hosting congresses, leisure events and exhibitions. Varghese [16]

\section{Role of DMO and Stakeholders in Crisis Management}

Tourism struggles under the burden of economic turbulence, terror attacks, like in New York, bomb attacks and even health related crises like Ebola, SARS, H1NI and so on. This has an indirect negative impact on present day tourism. Therefore destinations cannot be ignorant of crises and their tourism policy must effectively deal with these aspects as Borzyszkowski, and Marczak [4] elucidates the body that deals with destination crisis, " ...organizations which are to a considerable extent responsible for this problem are generally known as Destination Management Organizations (DMOs)" (p.38).

Paraskevas and Arendell [8] assess the role that Destination Management Organizations (DMOs) play in times of crisis with specific reference to man-made disasters such as terrorist attacks. Tourist destinations tend to be vulnerable to terrorist activities so the question is, how well the tourist destination is prepared for them. The paper discusses that DMOs have the responsibility of crisis management and the tourism stakeholders also have a major role in addressing the danger of terrorism, as the research argues that there's a lack of destination specific antiterrorism strategy which is necessary to bring about a proactive and tactical approach to dealing with crisis and disasters so as to improve the sense of security amongst visitors.

Borzyszkowski and Marczak [4] further explored the association amid destination management organizations and crisis situations that affect the tourist sector. The study was broadly focusing on two aspects first being to understand the influence of crisis situations on DMO and secondly to analyze the activities carried out by the DMO to regulate the negative impact of crisis in a destination. Modern DMOs do not stand for marketing destinations alone but has extended responsibilities.

Yeoman et al. [15] specifies the role of the DMO in a crisis as: "(1) developing a communications and contingency plan that deals with the terrorist events; (2) mapping marketing activities to deal with consumers' risk adverse behaviour; and (3) preparing themselves with simulation exercises to avoid an issue-reaction syndrome".

Thus modern DMOs execute several functions linked to management and also contributes towards the development of tourism in the given destination, so in case of a crisis the DMOs would have to play a major role, as the phenomenon of crises is not new, whereas it is only in the recent years that it has become the subject of broader analyses and studies, including the functioning of DMOs so crisis management is incorporated into DMO functionality.

The activities of a DMO are therefore in constant change as noted by Wagenseil [14] these changes would give rise to various challenges that the DMO would have to face. So with negative impacts affecting the destination the managers of DMOs must be equipped to recognize a critical situation which may have adverse impact on the destination. Moreover, there is also the need to arrange and practise those tools in order to prevent any such negative impacts. The Destination Management Organization (DMOs) deals with several categories, to bring to the highlight: destinations' overall management, competency of a destination, governance, quality 
control, stakeholder management, infrastructural development, marketing, and eventually leading to setting a benchmark that states a standard of quality services and products that is offered to the tourists and thereby achieve overall satisfaction of consumer. Varghese [13]

In order to find out the actions taken by the European Destination Management Organizations in tackling crises a survey was conducted by Borzyszkowski and Marczak [4] with the use of questionnaires sent to NTOs and NTAs. The two main questions asked were "how do you assess the impact of the crisis on your Organization?" and "What measures have been undertaken in order to limit the effects of the crisis in the state (destination)?" to which several response came. On analyzing the same the following results were identified first being the fact that several European DMOs took the crisis situation of New York as an opportunity to promote their destinations extensively such as the efforts of Visit Britain (the NTO of Great Britain) another important finding was the economic crisis was countered by Latvia in a positive manner as it enabled better coordination among the central government, local government and the private sector especially with relation to cost of promotion and representation of the state other countries sought various measures to combat crisis such as public - private, public public, private - private partnership, borrowing of funds from EU, breaking barriers that entrepreneurs faced by initiating new businesses and so on are mean that DMOs took to combating economic crisis. So crisis can be ironically advantageous to countries and the DMO should devise apt marketing efforts to utilize the opportunities presented, at the same time plan strategically to mitigate a crisis situation also.

\section{Crisis Management Inevitability: A Case of Uttarakhand Flash Flood Disaster in India}

Bisht (2013) speaks of the huge potential of the state of Uttarakhand in tourism leading to the state in tapping this potentially which lead to uncontrolled rise of tourist's inflow into the state; this took a negative toll on the delicate ecology of the region due to unrestrained tourism advancement. This route was most popular with pilgrimages to the temples of Badrinath, Kedarnath, Gangotri and other shrines, the trouble faced by tourists were the road connectivity was bad and hence to combat this the government widen the roads to accommodate the tourists travel inflow. The Himalayan region is known to have poor soil stability and the roads caves in or get washed away during monsoons. Besides this the rising tourism demand lured the construction of hotels and resort across the eco-sensitive zone which flouted environmental norms for example, Kedarnath Valley has hundreds of such hotels that were vulnerable to natural calamities. At the peak of the monsoon season the northern state of Uttarakhand was face to face with floods caused due to the cloud burst that hit three of the four famous Char Dham pilgrim sites, '2013 North India floods' (n.d.) that left tens and thousands of inhabitants as well as pilgrims stranded or swept away due to the floods, and not to mention the damage cause to life, property and business. The famous Char Dham pilgrimage is now discontinued for three years for repair and restoration ('Plan ahead', 2013). The National Institute of Disaster Management (NIDM), reported that the Uttarakhand floods, was caused due to, "climatic conditions combined with haphazard human intervention" leading to the disaster (Singh [11]). So, when flash floods struck the valley, many of these hotels were swept away and so did the people staying in them. There were no disaster management strategies in place and a lack of governance which resulted in unregulated tourism and illegal construction that wreaked havoc in this ecological hotspot.

Hence, the Destination Management Organization (DMO) must enforce a crisis management strategy alongside encourage the participation of stakeholders in the decision making process which would result in the collaborative efforts of the government and the stakeholders in assuring safety of tourists as well as environmental protection and be able to combat any crisis effectively. The various stances that the DMO can take in case of crisis are during the pre-event and prodromal stages, when appropriate measures are implemented to eliminate or minimize the destination weakness. DMOs can encourage the implementation of national anti -terrorism polices thus combating crises and helping in its prevention or mitigation.

\section{Conclusion}

There are several important roles the DMOs play other than promoting tourism destinations which is historically known to be the task of DMOs, the DMOs also have to maintain destination competitiveness, coordinate various stakeholder activities, product development, crisis management and whereas according to Ritchie and Crouch [10] "DMOs ensure the quality of the visitor's experience: visitor management; inflow and outflow of information; human resources development; resource stewardship; access to finance and venture capital; and crisis management". Lastly as Paraskevas and Arendell [8] explains the significance of stakeholders in planning the, "importance of particular destination stakeholders in the planning and implementation of the anti-terrorism strategy and the pivotal role of the DMO in coordinating the entire effort" (p.1570). Hence a healthy destination will have both parties the DMO and the stakeholders working hand in hand to build a credible tourism industry and also enable successful handling of crisis situations.

\section{References}

[1] 2013 North India floods. (n.d.). In Wikipedia the free encyclopaedia. Retrieved from http://en.wikipedia.org/wiki/2013_North_India_floods"

[2] Angella, F. D., Carlo, M. D., \& Sainaghi, R. (2010). Archetypes of destination governance: A comparison of international destinations. Tourism Review, 64(4), 61-73. doi: 10.1108/16605371011093872”. 
[3] Baggio, R., Scott, N., \& Cooper, C. (2010). Improving tourism destination governance: A complexity science approach. Tourism Review, 65(4), 51-60. doi: 10.1108/16605371011093863”.

[4] Borzyszkowski, J., \& Marczak, M. (n.d.). Destination management organizations in the face of crisis. I. Tourism and Heritage, $37 . \quad$ Retrieved from http://www.northseascreen.eu/File/CIT_konferencebog.pdf\#pa ge $=37$ '

[5] Bregoli, I., \& Del Chiappa, G. (2011, June). Destination governance and internal branding as antecedents of destination brand development: An exploratory study on Edinburgh. Istanbul, Turkey.”

[6] Del Chippa, G. (2010). Destination governance and branding: The Emerald Coast case study [PowerPoint slides]".

[7] Palmer, A. (1998). Evaluating the governance style of marketing groups. Annals of Tourism Research, 25(1), 185$201 "$.

[8] Paraskevas, A., \& Arendell, B. (2007). A strategic framework for terrorism prevention and mitigation in tourism destinations. Tourism Management, 28, 1560-1573. doi: 10.1016/j.tourman.2007.02.012”.

[9] Plan ahead: The recent devastations hold lesson on the need for preparation. (2013, June 24). Business India: The Magazine of the Corporate World, (921), 10. Retrieved from http://www.downtoearth.org.in/content/man-madereasonsuttarakhand-disaster"

[10] Ritchie, J., \& Crouch, G. (2003). The competitive destination (1st ed.). Oxon, UK: CABI Pub".

[11] Singh, J. (2013, June 18). Man-made reasons for Uttarakhand disaster. Down To Earth.

[12] Strobl, A., \& Peters, M. (2013). Entrepreneurial reputation in destination networks. Annals of Tourism Research, 40, 59-82. doi: 10.1016/j.annals.2012.08.005".

[13] Varghese, B. (2013). Intervention of destination management organization's in tourist destinations for branding, image building and competitiveness -A conducive model for Karnataka International Journal of Investment and Management, 2(3), 50-56. doi:10.11648/j.jim.20130203.13”.

[14] Wagenseil U., 2010. Destination \& DMO \&, Boundaries, Timisoara \& Fagaras, 25th \& 27th May 2010, Turism Durabil.ro, Unit for Sustainable Development of Tourism".

[15] Yeoman, I., Galt, M., \& McMahon-Beattie, U. (2005). A case study of how Visit Scotland prepared for war. Journal of Travel Research, 44, 6-20".

[16] Varghese, B. (2016). A strategic evaluation on competency of Karnataka destinations through destination management organizations American Journal of Industrial Business Management, 6(2), 102-108. doi: 10.4236/ojs.2011.13023”. 